\title{
Associations of physical activity with childhood asthma, a population study based on the WHO - health behaviour in school-aged children survey
}

\author{
Lene Lochte $^{1 *}$ (D) Poul Erik Petersen ${ }^{1}$, Kim G. Nielsen², Anette Andersen ${ }^{3}$ and Thomas A. E. Platts-Mills ${ }^{4}$
}

\begin{abstract}
Background: Asthma in paediatric populations is one of the highest public health concerns. In this study of children and adolescents, we hypothesized that low levels of physical activity (PA) would show associations with asthma that vary by asthma outcome. The objective was to assess whether PA was associated with ever asthma and/or current asthma.

Methods: Analyses were based on 4824 Danish schoolchildren aged 11-15 years old (48.7\% boys) participating in the HBSC survey. The study variables were (1) physician-diagnosed asthma (ever asthma) and (2) physician-diagnosed asthma plus wheezing and/or physician or hospital consultation for wheezing (current asthma). Associations with PA by gender were analysed with multivariate logistic regression using the "variance covariance (vce) cluster" method.

Results: The prevalence of ever asthma was 14.3\% (boys) and 12.8\% (girls), and that of current asthma was 6.8\% (boys) and 7. $0 \%$ (girls). Boys with current asthma showed important differences in low and high PA. We found inverse associations between low PA and ever asthma, odds ratio [95\% confidence interval] male: .55 [.30; .99] and female: .47 [.24; .93], and current asthma, male: .27 [.12; .60] (P linear trend $=.007$ ) and female: .32 [.11;.94].

Conclusions: The lowest activity levels showed significant inverse associations with asthma, regardless of the definition. For boys, the more stringent (current asthma) of the two paediatric asthma definitions revealed a significant trend with PA, and the direction of associations shifted to positive as weekly PA increased.
\end{abstract}

Keywords: Ever/or current asthmatic disease, PA, Paediatric, Children, Adolescents, HBSC, School survey

\section{Background}

Asthma in paediatric populations is a serious public health concern worldwide [1]. The associations between asthma and physical activity (PA) may be important for disease prevention and control $[2,3]$, but reports on the mechanisms behind this relationship are scarce [4]. Asthma is one of the most common lower respiratory diseases in children [5], and its increasing chronic and acute disease burden has caused considerable distress among national health authorities [6]. Similarly, people in most countries perform historically low levels of PA

\footnotetext{
* Correspondence: rkb664@alumni.ku.dk

${ }^{1}$ Department of Odontology, University of Copenhagen, 1014 Copenhagen, Denmark

Full list of author information is available at the end of the article
}

[7], and $80 \%$ do not fulfil the current international guidelines for PA [8]. Low PA in children has been proposed as one explanation for the so-called "asthma epidemic" [9].

The severity of paediatric asthma depends on the awareness of the disease condition in the population. The diagnosis of asthma is often made by a physician according to medical history and clinical symptoms [9]. However, the sharp increases in morbidity and mortality have not been explained by alterations in diagnostic practices [10]. Depending on the measurement methods used, asthma severity can influence cardiorespiratory fitness (CRF) [11]. In other paediatric studies, a questionable asthma diagnosis, i.e., with low sensitivity, has not revealed associations between asthma severity and maximal oxygen uptake [12].

(C) The Author(s). 2018 Open Access This article is distributed under the terms of the Creative Commons Attribution 4.0 International License (http://creativecommons.org/licenses/by/4.0/), which permits unrestricted use, distribution, and 
Given the worldwide variations in the occurrence of childhood asthma [6], it is often not clear which diagnosis of asthma to apply when analysing population data on children. In observational studies, data are frequently gathered by self-reported methods and rarely include clinical examinations.

Some studies have described associations of asthma in children with low PA [13, 14] or low CRF [15]. PA has been suggested to modify CRF in asthmatic and healthy children [16, 17]; however, asthma in children comprises a variety of symptom phenotypes [18], and effective preventions depend on determining the precise aetiology.

We hypothesized that low levels of PA in 11- to 15year-olds would show associations with childhood asthma that vary by asthma outcome. Therefore, the objective was to assess whether PA was associated with asthma when defined as ever asthma and/or current asthma during childhood and adolescence.

\section{Methods}

\section{Study population and participation rates}

We used Danish data that were part of the international World Health Organization (WHO)-coordinated Health Behaviour in School-aged Children (HBSC) survey [19]; the design was cross-sectional [20]. The HBSC aimed to increase the understanding of adolescents' lifestyle and its associations with healthy behaviours [21]. The study used repeated multi-country surveys conducted every four years, primarily in Europe. In Denmark, a survey was conducted six times from 1984 to 2002 . The HBSC protocol was standardized (sampling, data collection, compilation) and used self-completed, anonymous HBSC questionnaires administered at schools [22]. PA and asthma were measured for the first time in 1985 and 2002, respectively [21, 23].

The present data were collected from Feb-Apr 2002 and included all students in fifth, seventh, and ninth grade based on a random sample of Danish schools (the mean age in years: 11.6, 13.6, and 15.6, respectively). The 2002 survey comprised 68 schools with 5400 students in 297 classes. Of these, 4981 students (92.2\%) were present on the day of data collection, and $4824 \mathrm{stu}-$ dents (96.8\% of the students present) returned a completed questionnaire.

\section{Non-response}

There were two sources of non-response: i) schools, classes, and individuals who refused to participate and ii) absence on the data collection day. No follow-up was conducted for absent students. Of the 79 eligible schools, eleven (13.9\%) school authorities declined participation. The Danish part of the survey excluded $31(0$. 64\%) questionnaires due to missing information on gender or inappropriate responses.

\section{Measurements}

Outcome: Based on a validated asthma variable [23], we established two binary asthma definitions: ever asthma, defined by a positive response to the question "Has the doctor ever told you that you have asthma?", and current asthma, defined by a positive response to the question "Has the doctor ever told you that you have asthma?" plus a positive response to either "In the last 12 months, have you had episodes of wheezing?" or "In the last 12 months, have you had a consultation for wheezing by a doctor or in a hospital?"

The exposure was PA, which was recorded as responses to the following: "Outside of school hours, how many hours a week do you participate in sports or exercise that make you out of breath or sweaty?" There were six response options reported in hours (h) per week (wk) as follows: "0", “.5", "1", "2-3", "4-6", "> =7". The PA question on the HBSC survey [21] adhered to a validated standard based on Australian schoolchildren [24]. The following covariates were assessed: grade (fifth, seventh, ninth), self-rated health (poor, good, excellent), body mass index (BMI) $(13-15,16-18,19-21,>21$, defined as reported body weight in kilograms $(\mathrm{kg})$ divided by reported height in metres $(\mathrm{m})$ squared $\left(\mathrm{kg} \cdot \mathrm{m}^{-2}\right)$ ), and menarche (yes/no).

\section{Statistical methods}

Frequencies (\%) and means $( \pm 2 \mathrm{SD})$ were calculated. For the statistical evaluation, we applied the Chi-square test of homogeneity (Pearson's $X^{2}$ ). Spearman's correlation coefficient (rho) was assessed to express the correlations between physician-diagnosed asthma and the asthma symptom variables used to define the asthma outcomes in the children investigated.

Univariate analyses produced crude odds ratios (ORs) and 95\% confidence intervals (CIs) and assisted the identification of potential confounding variables (Additional file 1). A priori, we selected possible confounding variables using known influential variables and evidence from our univariate analyses. We applied the following criterion for a variable to possibly confound a given association: The variable (or groups of variables) demonstrated associations with the exposure, the outcome or both [25]. Additionally, MantelHaenszel stratification and likelihood ratio tests confirmed that BMI substantially influenced the associations under study. Formal tests of effect modification by self-rated health did not provide any response in these data $(P$ for interaction, male $=0.2004$, female $=0.3912$ ). Hence, the covariates adjusted for were as follows: grade and self-rated health (both genders), BMI (boys) (ever asthma only) and menarche (girls). We considered our analytical models along these lines and built them accordingly.

All analyses were conducted separately for males and females. For the outcome, we used two different definitions 
of childhood asthma. The results for ever asthma and current asthma are presented in this paper.

In the multivariate logistic regression models, we used the "variance covariance (vce) cluster" method, which calculated robust standard errors using schools as clusters. This approach allowed for correlated observations, e.g., potential effects of clusters induced by the HBSC sampling method. Hence, we estimated the associations, i.e., ORs (95\% CIs), for childhood asthma and PA exposure. High PA $\left(7^{+}\right.$hours per week) served as the reference, and we estimated the probability for linear trend. The selection of the reference group was based on tertiles of our exposure variable, and we adopted the criterion that more than $50 \%$ of the exposed should be in this group [26]. We used STATA ${ }^{\text {ma }}$ (v.12.1) (Stata Corp, College Station, TX, USA). All tests of significance were two-tailed, and $P<0.05$ was considered statistically significant, though strength against the null hypothesis was regarded as superior to the critical value set [27].

\section{Results}

Characteristics of the study participants are depicted in Table 1. A total of 4824 schoolchildren (48.7\% boys) participated. Table 1 shows the reported asthma symptoms (wheezing and doctor/hospital consultation for wheezing) for males and females. The prevalence of ever asthma was $14.3 \%$ for boys and $12.8 \%$ for girls; the current asthma prevalence was $6.8 \%$ in boys and $7.0 \%$ in girls. Table 2 shows the reported PA categories (low to high) distributed by male and female gender and

Table 1 Characteristics of all study participants (\%) by gender

\begin{tabular}{llll}
\hline & $\begin{array}{l}\text { Boys (n) } \\
\text { 48.7 (2348) }\end{array}$ & $\begin{array}{l}\text { Girls (n) } \\
51.3(2476)\end{array}$ & $P$ \\
\hline Participants by grade & & & $=0.462$ \\
5 & $35.6(836)$ & $37.0(916)$ & \\
7 & $34.4(807)$ & $32.8(812)$ & \\
9 & $30.0(705)$ & $30.2(748)$ & \\
Wheeze ${ }^{\text {AS }}$ & $14.2(333)$ & $17.2(426)$ & $=0.003$ \\
$\quad$ Mis & $1.3(31)$ & $1.6(40)$ & \\
Doctor /or hospital & $6.4(151)$ & $7.0(172)$ & $=0.481$ \\
consultation for wheeze & & & \\
$\quad$ Mis & $1.0(23)$ & $0.9(21)$ & \\
Ever asthma & $14.3(336)$ & $12.8(316)$ & $=0.120$ \\
$\quad$ Mis & $0.8(18)$ & $0.9(22)$ & \\
Current asthma & $6.8(160)$ & $7.0(173)$ & $=0.806$ \\
$\quad$ Mis & $2.3(53)$ & $2.3(58)$ & \\
Low PA (0-1 h/week) & $24.5(568)$ & $33.1(810)$ & $<0.001$ \\
$\quad$ Mis & $1.1(25)$ & $1.1(28)$ & \\
\hline
\end{tabular}

AS Asthma symptom past 12 months, $H$ Hour, Mis Missing, $N$ Number, Ns Nonsignificant, $P$ Probability of difference between genders (Pearson $\left.\mathrm{chi}^{2}\right), P A$ Physical activity
Table 2 Distribution (\%) of weekly PA according to ever asthma for participating boys and girls

\begin{tabular}{llll}
\hline PA (h per wk.) & Boys $(n)$ & Girls $(n)$ & $P^{a}$ \\
\hline Low (0-1) & $22.2(74)$ & $29.5(93)$ & $=0.408$ \\
Mod (2-3) & $28.7(96)$ & $34.3(108)$ & $=0.490$ \\
High (4-7+) & $49.1(164)$ & $36.2(114)$ & $=0.498$ \\
$P^{b}$ & $=0.524$ & $=0.323$ & \\
\hline
\end{tabular}

$H$ Hour/s, Mod Moderate, $N$ Number, $P$ Probability of difference (Pearson chi ${ }^{2}$ ) between (a) genders, (b) PA categories, PA Physical activity, Wk Week Overall Pearson chi $^{2}: P=0.003$

according to ever asthma (Table 2) and current asthma (Table 3). Boys with current asthma exhibited important differences in low and high PA. Details of the univariate associations for ever asthma and current asthma are presented in Additional file 1. Additional file 2 presents the correlations (Spearman's rho, r) for physician-diagnosed asthma and the asthma symptom variables used to define the respective outcomes, i.e., ever asthma and current asthma. Table 4 and Table 5 present the crude and adjusted associations, OR and $95 \% \mathrm{CI}$, for PA $\left(0-7^{+}\right.$ hours per week) and ever asthma and current asthma, respectively. After adjustments, we found inverse associations (i.e., possible protective associations) between PA and asthma using both definitions. With ever asthma, inverse associations were present in boys reporting zero hours of PA per week and for girls reporting $0-1 \mathrm{~h}$ of PA per week, with risk reductions of $45 \%$ and $53 \%$ in males and females, respectively (Table 4). For current asthma, inverse associations were present for boys reporting zero hours of PA per week and for girls reporting $.5 \mathrm{~h}$ of PA per week, with risk reductions of $73 \%$ and $68 \%$ in males and females, respectively (Table 5). For current asthma, there was a significant trend $(P=.007)$ in boys (Table 5), and the associations shifted in a positive direction as weekly PA increased. There was evidence of an attenuation of effects for ever (Table 4) and current asthma (Table 5) in both males and females after adjusting for possible confounders.

\section{Discussion}

In this population of schoolchildren, our key finding from the cross-sectional data was that low PA showed significant inverse associations, regardless of asthma

Table 3 Distribution (\%) of weekly PA according to current asthma for participating boys and girls

\begin{tabular}{llll}
\hline PA (h per wk.) & Boys $(n)$ & Girls $(n)$ & $P^{a}$ \\
\hline Low (0-1) & $16.4(26)$ & $27.2(47)$ & $=0.296$ \\
Mod (2-3) & $28.3(45)$ & $36.4(63)$ & $=0.509$ \\
High (4-7+) & $55.4(88)$ & $36.4(63)$ & $=0.749$ \\
$P^{b}$ & $=0.025$ & $=0.229$ &
\end{tabular}

$H$ Hour/s, Mod Moderate, $N$ Number, $P$ Probability of difference (Pearson chi ${ }^{2}$ ) between (a) genders, (b) PA categories, PA Physical activity, Wk Week Overall Pearson $\mathrm{chi}^{2}: P=0.002$ 
Table 4 Crude and adjusted associations for ever asthma i.e. Asthma Definition [1] by physical activity categorised (0-7 $7^{+}$hours per week), odds ratio and 95\% confidence interval

\begin{tabular}{|c|c|c|}
\hline & Boys & Girls \\
\hline "Ever Asthma" (\%, n, total) & $(14.4,336,2330)$ & $(12.9,316,2454)$ \\
\hline PA (all categories) (n) & 2323 & 2448 \\
\hline 0 h/wk. $(\%, n)$ & $9.3,216$ & $11.2,275$ \\
\hline Crude OR $(95 \% \mathrm{Cl})^{\mathrm{a}}$ & $0.70(0.40 ; 1.22)^{P=0.207}$ & $0.79(0.52 ; 1.19)^{p=0.255}$ \\
\hline Adjusted OR $(95 \% \mathrm{Cl})^{\mathrm{b}}$ & $0.55(0.30 ; 0.99)^{P=0.046}$ & $0.62(0.40 ; 0.97)^{P=0.034}$ \\
\hline 0.5 h/wk. $(\%, n)$ & $5.6,129$ & $6.3,153$ \\
\hline Crude OR $(95 \% \mathrm{Cl})^{\mathrm{a}}$ & $0.94(0.50 ; 1.77)^{P=0.840}$ & $0.60(0.32 ; 1.12)^{P=0.109}$ \\
\hline Adjusted OR $(95 \% \mathrm{Cl})^{\mathrm{b}}$ & $0.73(0.35 ; 1.53)^{P=0.409}$ & $0.47(0.24 ; 0.93)^{P=0.030}$ \\
\hline 1 h/wk. $(\%, n)$ & $9.6,223$ & $15.6,382$ \\
\hline Crude OR $(95 \% \mathrm{Cl})^{\mathrm{a}}$ & $1.16(0.70 ; 1.91)^{P=0.576}$ & $0.69(0.43 ; 1.12)^{P=0.136}$ \\
\hline Adjusted OR $(95 \% \mathrm{Cl})^{\mathrm{b}}$ & $0.96(0.53 ; 1.74)^{P=0.897}$ & $0.60(0.37 ; 0.98)^{P=0.039}$ \\
\hline 2-3 h/wk. $(\%, n)$ & $28.6,664$ & $33.5,819$ \\
\hline Crude OR $(95 \% \mathrm{Cl})^{\mathrm{a}}$ & $1.05(0.77 ; 1.43)^{P=0.746}$ & $0.83(0.57 ; 1.21)^{P=0.332}$ \\
\hline Adjusted OR $(95 \% \mathrm{Cl})^{\mathrm{b}}$ & $1.00(0.70 ; 1.42)^{P=0.982}$ & $0.73(0.50 ; 1.07)^{P=0.104}$ \\
\hline 4-6 h/wk. $(\%, n)$ & $27.2,631$ & $22.4,549$ \\
\hline Crude OR $(95 \% \mathrm{Cl})^{\mathrm{a}}$ & $1.17(0.88 ; 1.56)^{P=0.270}$ & $0.82(0.53 ; 1.28)^{P=0.383}$ \\
\hline Adjusted OR $(95 \% \mathrm{Cl})^{\mathrm{b}}$ & $1.17(0.84 ; 1.62)^{P=0.353}$ & $0.72(0.45 ; 1.15)^{\rho}=0.171$ \\
\hline $7+$ h/wk. $(\%, n)$ & $19.8,460$ & $11.0,270$ \\
\hline Ref & 1.00 & 1.00 \\
\hline$P$ linear trend & $=0.235$ & $=0.189$ \\
\hline
\end{tabular}

HBSC Health Behaviour in School-aged Children, $H$ Hour/s, Mod Moderate, Ref Reference category, WHO World Health Organization, Wk Week

a Univariate analysis i.e. crude effect of PA ( $n$ boys: $2311 ; n$ girls: 2429 )

bMultivariate analysis i.e. "full confounder adjustment model" ( $n$ boys: 2058; $n$ girls: 2347)

Adjustments (male: Grade, self-rated health, BMI; female: Grade, self-rated health, menarche)

$\mathrm{P:} \mathrm{Chi}^{2}$

diagnosis. In addition, high PA among boys demonstrated positive effects, suggesting elevated asthma risks. We confirmed this finding by identifying a positive dose-response for boys with current asthma.

Our study sample was nationally representative, but our results can be compared with those of international HBSC collaborators [23] as well. Our results are consistent with those of other authors in addition to the HBSC. For example, although the findings were not reported separately for boys and girls, current asthma reports show null effects for lower activity levels and increased risk with PA exceeding $7 \mathrm{~h}$ per week [28]. Although asthmatic children and adolescents can be as physically active as healthy children $[28,29]$, they may still demonstrate lower CRF [30]. The current study determined that PA is a behavioural factor that varies by context and time, whereas CRF is genetically determined and therefore tends to remain stable over time [31]. Additionally, our results seem to support a previous study investigating sports frequency and incident wheezing in paediatric populations [14]. That study found inverse associations of higher activity in boys and girls [14], and based on the validated PA measure ("active": one hour or more per week) [24] used in the HBSC survey, it is plausible that the activity frequency reported by our colleagues [14] is comparable to our results for $1-3 \mathrm{~h}$ of PA per week. In addition, the "leisure-type PA outside school hours" assessed in our HBSC data may be similar to the swimming and running that our colleagues [14] studied. The current study did not measure CRF, and thus we cannot rule out that certain weekly running programmes may have decreased exercise-induced bronchoconstriction [32] and subsequently protected against wheezing.

The selection of participating schoolchildren by "cluster sampling" may introduce selection bias. To account for this design effect, we adjusted our final analyses to account for non-independent variables. A computerassisted random selection of the eligible schools was performed, and we reviewed the initial non-responses in eleven schools. According to the study protocol, the reasons for refusing participation were within the frequently reported categories, for example, administrative overload or recent participation in another survey. The participating schools were both private and public, and social class did not influence our findings; in contrast to the International Study of Asthma and Allergies in Childhood 
Table 5 Crude and adjusted associations for current asthma i.e. Asthma Definition [2] by physical activity categorised (0-7 $7^{+}$hours per week), odds ratio and 95\% confidence interval

\begin{tabular}{|c|c|c|}
\hline & Boys & Girls \\
\hline "Current Asthma" (\%, n, total) & $(7.0,160,2295)$ & $(7.2,173,2418)$ \\
\hline PA (all groups) (n) & 2323 & 2448 \\
\hline 0 h/wk. $(\%, n)$ & $9.3,216$ & $11.2,275$ \\
\hline Crude OR $(95 \% \mathrm{Cl})^{\mathrm{a}}$ & $0.45(0.20 ; 1.03)^{P=0.060}$ & $0.81(0.41 ; 1.57)^{P=0.528}$ \\
\hline Adjusted OR $(95 \% \mathrm{Cl})^{\mathrm{b}}$ & $0.27(0.12 ; 0.60)^{P=0.002}$ & $0.56(0.28 ; 1.14)^{P=0.108}$ \\
\hline 0.5 h/wk. $(\%, n)$ & $5.6,129$ & $6.3,153$ \\
\hline Crude OR $(95 \% \mathrm{Cl})^{\mathrm{a}}$ & $0.76(0.33 ; 1.78)^{P=0.529}$ & $0.52(0.21 ; 1.32)^{P=0.171}$ \\
\hline Adjusted OR $(95 \% \mathrm{Cl})^{\mathrm{b}}$ & $0.48(0.20 ; 1.16)^{P=0.102}$ & $0.32(0.11 ; 0.94)^{P=0.039}$ \\
\hline 1 h/wk. $(\%, n)$ & $9.6,223$ & $15.6,382$ \\
\hline Crude OR $(95 \% \mathrm{Cl})^{\mathrm{a}}$ & $0.77(0.40 ; 1.46)^{P=0.417}$ & $0.63(0.31 ; 1.27)^{P=0.198}$ \\
\hline Adjusted OR $(95 \% \mathrm{Cl})^{\mathrm{b}}$ & $0.55(0.28 ; 1.06)^{P=0.073}$ & $0.52(0.26 ; 1.01)^{P=0.055}$ \\
\hline 2-3 h/wk. $(\%, n)$ & $28.6,664$ & $33.5,819$ \\
\hline Crude OR $(95 \% \mathrm{Cl})^{\mathrm{a}}$ & $0.99(0.62 ; 1.58)^{P=0.981}$ & $0.91(0.51 ; 1.63)^{P=0.74 t}$ \\
\hline Adjusted OR $(95 \% \mathrm{Cl})^{\mathrm{b}}$ & $0.76(0.46 ; 1.27)^{P=0.299}$ & $0.82(0.46 ; 1.46)^{P=0.496}$ \\
\hline 4-6 h/wk. $(\%, n)$ & $27.2,631$ & $22.4,549$ \\
\hline Crude OR $(95 \% \mathrm{Cl})^{\mathrm{a}}$ & $1.34(0.83 ; 2.15)^{P=0.231}$ & $0.85(0.44 ; 1.64)^{P=0.631}$ \\
\hline Adjusted OR $(95 \% \mathrm{Cl})^{\mathrm{b}}$ & $1.21(0.72 ; 2.03)^{P=0.479}$ & $0.77(0.39 ; 1.51)^{\rho}=0.444$ \\
\hline $7+h / w k .(\%, n)$ & $19.8,460$ & $11.0,270$ \\
\hline Ref & 1.00 & 1.00 \\
\hline$P$ linear trend & $=0.007$ & $=0.229$ \\
\hline
\end{tabular}

HBSC Health Behaviour in School-aged Children, $H$ Hour/s, Mod Moderate, Ref Reference category, WHO World Health Organization, Wk Week a Univariate analysis i.e. crude effect of PA ( $n$ boys: 2277 ; $n$ girls: 2397 )

${ }^{b}$ Multivariate analysis i.e. "full confounder adjustment model" ( $n$ boys: 2265; $n$ girls: 2319)

Adjustments (male: Grade, self-rated health; female: Grade, self-rated health, menarche)

P: $\mathrm{Chi}^{2}$

(ISAAC)'s urban records [33], our HBSC data in mixed rural and urban contexts likely exhibited substantial variability, which improved the accuracy of the measurements. Thus, the factors discussed seem to support a sound representativeness of our data.

The attenuation of effects that we observed from the crude to the adjusted results is consistent with others' observations [34]. Some previous studies also found positive associations between low PA and childhood asthma but with certain restrictions. For example, the results of a study with New Zealand children, who are sometimes considered comparable to Scandinavian populations, indicated inverse effects in children but not in adolescents [13]. Although our two studies both investigated vigorous activities, the asthma diagnoses varied. In contrast to the HBSC, ISAAC [13] included parental assistance for the youngest children. We adjusted for grade to represent the age of the students, as this factor confounded the associations. However, other colleagues noted that, compared to the children, the parents of asthmatic children reported more PA [35]. Moreover, the children we studied could have been providing information about, e.g., a viral infection [12,33]; based on the questions about asthma that involved contact with physicians or the hospital, the risk of non-random misclassification seems low, but this possibility could have been assessed quantitatively using sensitivity analyses [36]. Additionally, our results for the male participants seem to agree with recent findings that demonstrate positive associations between high PA and asthma [37]. These authors [37] studied club sports, and it is likely that our assessment of after-school PA represent organized activities as well; therefore, our two studies may already be comparable with respect to basic data.

An advantage of the current study is that the PA variable had been validated previously demonstrating acceptable validity and reliability and that a relevant reference was used, as the Australian population is often comparable to European populations [24]. Our findings for PA may align with previous results, which suggest that season of the year and low PA are associated [38]. Our data were collected in the spring; in Denmark, this time of the year typically reflects an increase in children's participation in outdoor PA. The partially comparable pattern of PA for boys and girls in the reported after-school activities seem consistent with findings 
measured using accelerometry [39]; it is clear that the overall variances in these two studies pertained to the high-intensity leisure-time PA performed by the participating boys. Overall, the two asthma outcomes elucidated how asthma in young populations can be expressed using epidemiological data. One advantage of the current findings is the fairly consistent results of the broader and the more restrictive outcome. While the definition of ever asthma is well-established, current asthma has been studied using varying definitions [40, 41]. Earlier comparisons of ever asthma and wheezing show higher prevalence of wheezing, although wheezing still showed reasonable sensitivity and specificity [33]. Current asthma is likely to represent a more severe variation of asthma symptoms, as the prevalence using this definition was nearly half that of ever asthma.

The self-reported nature of our data may be a limitation. The type of report used is highly important to asthma outcomes, which are based on children's ability to recall that a physician told them that they have asthma. Although we identified a relatively high prevalence of ever asthma, this rate was consistent with the global [6] and HBSC prevalence [42]. In fact, the study that validated the HBSC asthma questions [23] found that significantly more parents than children reported "diagnosed as having asthma". In our study, we cannot exclude that some slight overreporting of both ever and current asthma may have overestimated the prevalence obtained. Additionally, in our analyses, we did not distinguish between younger and older children, but the youngest children in our sample were 11 years of age; hence, as generally seen in the HBSC surveys, there could be less accurate reporting of factors 12 months prior to the survey, particularly by the youngest children. The ISAAC contributed in part to the HBSC asthma questions, but we propose that any discrepancy in reporting by age groups of those 11 (HBSC) and 13 (ISAAC) years would have limited impact on our results. The HBSC asthma questions are based on the Brief Pediatric Asthma Screening (BPAS) questionnaire, which has reasonable sensitivity and only minor misclassification [23]. These findings support our argument that the present HBSC data are valid.

The severity of paediatric asthma studied was indirectly included in the asthma symptom questions. In addition to wheezing, we used a second symptom, "doctor or hospital consultation for wheezing". This approach is standard in epidemiological studies of asthma in children [41]. In the original scale validation of the HBSC asthma questions, these two symptoms both obtained high scores [23]. While type of PA was not specified in the HBSC questionnaire, the PA question asked about activities that led to "sweating" or "getting out of breath". In line with earlier findings [43], it is possible that some of the children in our study had mild or moderate asthma, as high PA was well represented, particularly by the boys. We cannot directly distinguish the asthmogeneity of the activities reported by the children, but the HBSC protocol states that PA should be of the "moderate-to-vigorous" intensity. The HBSC asthma questions do not ask about participants' medical treatment for asthma, and thus the proxy we used was "consultation for wheezing by a doctor or in a hospital" to represent any exacerbation of respiratory symptoms that required medical attention. As this question asked about a hospital episode, the risk of recall bias was considered low. Asthmatic children may need medical treatment to participate in the high-intensity sports reported. As we used child-reported data as opposed to parental reports, the risk of systematic overreporting was not apparent. The lack of a reference time [24], which is equally important to self-reported asthma and the PA of the children surveyed in HBSC, may be a limitation. Thus, memory cues for PA, for example, "within a fortnight" or "on weekdays", likely could have improved the accuracy of the self-reports provided by the children. The limitations associated with children's self-reported PA are widely recognised [44]; although our PA data do not provide information on all PA dimensions, the pattern of our results for PA and asthma from the current Danish HBSC study aligns with that of other European countries [7]. We observed some indications of boys with asthma being more physically active on a weekly basis than girls with asthma. This finding further suggests that boys and girls with asthmatic diseases and those in the background population follow similar patterns with regard to their PA. Meanwhile, our data for the asthmatic boys and girls clearly showed that two-thirds reported activity levels above the recommended European standard of 60 min per day.

Finally, the questionnaire data revealed no obvious gender differences for any of the asthma types. This finding is in line with earlier findings-at least for low PA levels [45]; however, supplementary activity monitoring at the leisure settings may have improved our design and the ability of the methods to detect any gender discrepancy.

The current data were cross-sectional, and caution is thus warranted in interpreting our findings as causeand-effect. We did not ascertain the directions of the associations, and our results could be subject to reverse causation. However, in other cross-sectional designs, our colleagues $[40,46]$ analysed the opposite order of events, i.e., childhood asthma was defined as the exposure. One of these studies [40] demonstrated an association between severe asthma in children and low PA. This association may support our findings for some participants. The other study [46] demonstrated that children with asthma had a good chance of performing moderate 
activity, which is consistent with our observations; nonetheless, the temporal sequence of our results cannot be accounted for by the present point observations. Furthermore, the HBSC design ensured the total anonymity of participants, which precluded us from tracking our participants over time. While we were unable to detect the future direction of the associations, overall, cross-sectional studies of asthma in children use heterogeneous methodologies [47], and thus future comparisons highly depend on the application of a systematic approach.

\section{Conclusions}

The lowest PA levels showed significant inverse associations with asthma, regardless of the definition. For boys, the more stringent (current asthma) of the two paediatric asthma definitions revealed a significant trend with $\mathrm{PA}$, and the associations shifted in a positive direction as weekly PA increased.

\section{Additional files}

Additional file 1: Univariate analyses. Presents univariate analyses for PA, covariates, Ever Asthma (Tables 15, 16); PA, covariates, Current Asthma (Tables 15 $1{ }^{1}, 16^{1}$ ); covariates, PA (Table 17). (PDF $133 \mathrm{~kb}$ )

Additional file 2: Correlation matrix. Presents correlations for asthma variables. (DOCX $23 \mathrm{~kb}$ )

\section{Abbreviations}

BMI: Body mass index; BPAS: Brief Pediatric Asthma Screening; CRF: Cardiorespiratory fitness; HBSC: Health Behaviour in School-aged Children; ISAAC: International Study of Asthma and Allergies in Childhood; PA: Physical activity; WHO: World Health Organization

\section{Acknowledgements}

The current study was conducted as a postdoctoral research project of the first author LL upon completion of her PhD programme at the Faculty of Health and Medical Sciences, University of Copenhagen, Copenhagen, Denmark. LL wishes to express her gratitude to the PhD School and Department of Odontology, University of Copenhagen, and to Professor Bjoern E. Holstein, National Institute of Public Health, University of Southern Denmark, Copenhagen, Denmark.

The authors also wish to thank the Section of Biostatistics, Department of Public Health, University of Copenhagen. In particular, Professor Thomas Scheike (TS) is acknowledged for the review and guidance of the multivariate adjustments. American Journal Experts provided professional editing for the first draft of the manuscript and tables (except Af1 and Af2).

The study used data from the Danish part of the international research project Health Behaviour in School-aged Children (HBSC) - a WHO crossnational survey. The Principal Investigator in Denmark, Dr. Pernille Due from the National Institute of Public Health, Copenhagen, provided the data.

\section{Funding}

Neither the HBSC Steering Group to Denmark (AA) nor the author group (PEP, KGN, TAEPM, and LL) had separate funding available for the implementation of this study.

\section{Availability of data and materials}

Data are available from the corresponding author upon reasonable request.

\section{Authors' contributions}

PEP, KGN, TAEPM, and LL designed this study. AA conceived the questioning regarding asthma symptoms based on the WHO-coordinated HBSC survey. The questionnaires were distributed and data collected and collated by national representatives of the HBSC. LL analysed the data and received statistical guidance from TS. AA, PEP, KGN, TAEPM, and LL, assisted by TS, interpreted the results. All authors read and provided their approval of the final manuscript.

\section{Ethics approval and consent to participate}

In Denmark, when questionnaire-based population studies do not involve human biological material, the ethical authority is the local institution. As is customary for the HBSC [48] survey, we obtained ethical approval from each school's board of parents and students' council, and we informed the students - orally and in writing - that their participation was voluntary and anonymous. The HBSC protocol complied with the Declaration of Helsinki II.

\section{Consent for publication}

Not applicable because individual data are not presented in the manuscript.

\section{Competing interests}

The authors declare that they have no competing interests.

\section{Publisher's Note}

Springer Nature remains neutral with regard to jurisdictional claims in published maps and institutional affiliations.

\section{Author details}

'Department of Odontology, University of Copenhagen, 1014 Copenhagen, Denmark. ${ }^{2}$ Department of Paediatrics and Adolescent Medicine, Copenhagen University Hospital, Rigshospitalet, 2100 Copenhagen, Denmark. ${ }^{3}$ National Institute of Public Health, University of Southern Denmark, 1455 Copenhagen, Denmark. ${ }^{4}$ Department of Medicine, Division of Allergy and Clinical Immunology, University of Virginia, Charlottesville, VA 22908, USA.

Received: 1 August 2017 Accepted: 5 April 2018

Published online: 30 April 2018

\section{References}

1. World Health Organization. Asthma. Geneva: World Health Organization. 2013. Available: http://www.who.int/mediacentre/factsheets/fs307/en/. Accessed 26 Jan 2018.

2. Platts-Mills TAE. Asthma severity and prevalence: an ongoing interaction between exposure, hygiene, and lifestyle. PLoS Med. 2005;2(2):e34.

3. Clark CJ, Cochrane LM. Physical activity and asthma. Curr Opin Pulm Med. 1999;5(1):68-75.

4. Asher MI, Montefort S, Bjorksten B, Lai CKW, Strachan DP, Weiland SK, et al. Worldwide time trends in the prevalence of symptoms of asthma, allergic rhinoconjunctivitis, and eczema in childhood: ISAAC phases one and three repeat multicountry cross-sectional surveys.[erratum appears in lancet. 2007 Sep 29;370(9593):1128]. Lancet. 2006;368(9537):733-43.

5. Papadopoulos NG, Arakawa H, Carlsen KH, Custovic A, Gern J, Lemanske R, et al. International consensus on (ICON) pediatric asthma. Allergy. 2012; 67(8):976-97.

6. Lai CKW, Beasley R, Crane J, Foliaki S, Shah J, Weiland S, et al. Global variation in the prevalence and severity of asthma symptoms: phase three of the international study of asthma and allergies in childhood (ISAAC). Thorax. 2009;64(6):476-83.

7. World Health Organization. Physical activity 10 key facts on physical activity in the WHO European Region. Geneva: World Health Organization. 2016. Available: http:/www.euro.who.int/en/health-topics/disease-prevention/ physical-activity/data-and-statistics/10-key-facts-on-physical-activity-in-thewho-european-region/. Accessed 18 Jan 2018.

8. Hallal PC, Andersen LB, Bull FC, Guthold R, Haskell W, Ekelund U. Global physical activity levels: surveillance progress, pitfalls, and prospects. Lancet. 2012;380(9838):247-57.

9. Eder W, Ege MJ, von Mutius E. The asthma epidemic. New Engl J Med. 2006;355(21):2226-35.

10. Burney PGJ, Chinn S, Rona RJ. Has the prevalence of asthma increased in children? Evidence from the National Study of Health and Growth 1973-86. BMJ. 1990;300(6735):1306-10.

11. Varray A, Mercier J, Savy-Pacaux AM, Prefaut C. Cardiac role in exercise limitation in asthmatic subjects with special reference to disease severity. Eur Respir J. 1993;6(7):1011-7. 
12. Pianosi PT, Davis HS. Determinants of physical fitness in children with asthma. Pediatrics. 2004;113(3):e225-9.

13. Mitchell E, Beasley R, Björkstén B, Crane J, García-Marcos L, Keil U. The association between BMl, vigorous physical activity and television viewing and the risk of symptoms of asthma, rhinoconjunctivitis and eczema in children and adolescents: ISAAC phase three. Clin Exp Allergy. 2013;43(1): 73-84.

14. Vogelberg $\mathrm{C}$, Hirsch $\mathrm{T}$, Radon $\mathrm{K}$, Dressel H, Windstetter D, Weinmayr $\mathrm{G}$, et al. Leisure time activity and new onset of wheezing during adolescence. Eur Respir J. 2007;30(4):672-6.

15. Rasmussen F, Lambrechtsen J, Siersted H, Hansen H, Hansen N. Low physical fitness in childhood is associated with the development of asthma in young adulthood: the Odense schoolchild study. Eur Respir J. 2000;16(5):866-70.

16. Graff-Lonnevig V, Bevegard S, Eriksson BO, Kraepelien S, Saltin B. Two years' follow-up of asthmatic boys participating in a physical activity programme. Acta Pediatr Scand. 1980;69(3):347-52.

17. World Health Organization. Children's environmental health, Children, mobility and environmental health. World Health Organization. Available: http://www.who.int/ceh/risks/cehmobility/en/. Accessed 26 Jan 2018.

18. Granell R, Sterne JAC, Henderson J. Associations of different phenotypes of wheezing illness in early childhood with environmental variables implicated in the Aetiology of asthma. PLoS One. 2012;7(10):e48359.

19. World Health Organization. Young People's Health in Context. Health Behaviour in School-aged Children (HBSC) study: international report from the 2001/2002 survey. Copenhagen: World Health Organization. 2004. Available: http://www.euro.who.int/en/publications/key-publications/. Accessed 26 Jan 2018

20. Roberts C, Currie C, Samdal O, Currie D, Smith R, Maes L. Measuring the health and health behaviours of adolescents through cross-national survey research: recent developments in the health behaviour in school-aged children (HBSC) study. J Public Health. 2007;15(3):179-86.

21. Currie C, Gabhainn NS, Godeau E. The health behaviour in school-aged children: WHO collaborative cross-national (HBSC) study: origins, concept, history and development 1982-2008. Int J Public Health. 2009;54(2):131-9.

22. Roberts C, Freeman J, Samdal O, Schnohr CW, de Looze ME, Gabhainn NS, et al. The health behaviour in school-aged children (HBSC) study: methodological developments and current tensions. Int J Public Health. 2009:54(2):140-50.

23. Hublet A, Bacquer DD, Vereecken C, Maes L. Value of a shortened questionnaire in the description of asthma in 10-12-year-old pupils. Pediatr Allergy Immunol. 2004;15(3):247-52.

24. Booth ML, Okely AD, Chey T, Bauman A. The reliability and validity of the physical activity questions in the WHO health behaviour in schoolchildren (HBSC) survey: a population study. Br J Sports Med. 2001;35(4):263-7.

25. Hernán MA, Hernández-Díaz S, Werler MM, Mitchell AA. Causal knowledge as a prerequisite for confounding evaluation: an application to birth defects epidemiology. Am J Epidemiol. 2002;155(2):176-84.

26. Kirkwood BR, Sterne JAC. Regression modelling. In: Kirkwood BR, Sterne JAC, editors. Essential Medical Statistics. Oxford: Blackwell Science; 2003. p. 321.

27. Sterne JAC, Smith GD. Sifting the evidence - what's wrong with significance tests? BMJ. 2001;322(7280):226-31.

28. Nystad W. The physical activity level in children with asthma based on a survey among 7-16-year-old school children. Scand J Med Sci Sports. 1997; 7(6):331-5.

29. van Gent $R$, van der Ent CK, van Essen-Zandvliet LEM, Rovers MM, Kimpen $J L L$, de Meer $G$, et al. No differences in physical activity in (un)diagnosed asthma and healthy controls. Pediatr Pulmonol. 2007:42(11):1018-23.

30. Lochte L, Angermann M, Larsson B. Cardiorespiratory fitness of asthmatic children and validation of predicted aerobic capacity. Clin Respir J. 2009; 3(1):42-50.

31. Kemper HCG, Twisk JWR, Koppes LL, van Mechelen W, Post GB. A 15-year physical activity pattern is positively related to aerobic fitness in young males and females (13-27 years). Eur J Appl Physiol. 2001;84(5):395-402.

32. Weiler JM, Anderson SD, Randolph C, Bonini S, Craig TJ, Pearlman DS. Pathogenesis, prevalence, diagnosis, and management of exercise-induced bronchoconstriction: a practice parameter. Ann Allerg Asthma Im. 2010; 105(6 Suppl):S1-S47.

33. Patel SP, Jarvelin M-R, Little MP. Systematic review of worldwide variations of the prevalence of wheezing symptoms in children. Environ Health. 2008; 7(1):57.
34. Sherriff A, Maitra A, Ness AR, Mattocks C, Riddoch C, Reilly JJ, et al. Association of duration of television viewing in early childhood with the subsequent development of asthma. Thorax. 2009;64(4):321-5.

35. Ownby D, Peterson E, Nelson D, Joseph C, Williams L, Johnson C. The relationship of physical activity and percentage of body fat to the risk of asthma in 8- to 10-year-old children. J Asthma. 2007;44(10):885-9.

36. Jurek AM, Greenland S, Maldonado G. How far from non-differential does exposure or disease misclassification have to be to bias measures of association away from the null? Int J Epidemiol. 2008;37(2):382-5.

37. Islam T, Berhane K, McConnell R, Gauderman WJ, Avol E, Peters JM, et al. Glutathione-S-transferase (GST) P1, GSTM1, exercise, ozone and asthma incidence in school children. Thorax. 2009;64(3):197-202.

38. King AC, Parkinson KN, Adamson AJ, Murray L, Besson H, Reilly JJ, et al. Correlates of objectively measured physical activity and sedentary behaviour in English children. Eur J Pub Health. 2011;21(4):424-31.

39. Riddoch CJ, Mattocks C, Deere K, Saunders J, Kirkby J, Tilling K, et al. Objective measurement of levels and patterns of physical activity. Arch Dis Child. 2007;92(11):963-9.

40. Lang DM, Butz AM, Duggan AK, Serwint JR. Physical activity in Urban School-aged children with asthma. Pediatrics. 2004;113(4):e341-6.

41. Nystad W, Nafstad P, Harris J. Physical activity affects the prevalence of reported wheeze. Eur J Epidemiol. 2001;17(3):209-12.

42. Hublet A, De Bacquer D, Boyce W, Godeau E, Schmid H, Vereecken C, et al. Smoking in young people with asthma. J Public Health. 2007;29(4):343-9.

43. Counil F-P, Varray A, Matecki S, Beurey A, Marchal P, Voisin M, et al. Training of aerobic and anaerobic fitness in children with asthma. J Pediatr. 2003; 142(2):179-84

44. Sallis JF, Saelens BE. Assessment of physical activity by self-report: status, limitations, and future directions. Res Q Exerc Sport. 2000;71(2 Suppl):S1S14.

45. Janz KF, Witt J, Mahoney LT. The stability of children's physical activity as measured by accelerometry and self-report. Med Sci Sports Exerc. 1995; 27(9):1326-32

46. Jones S, Merkle S, Fulton J, Wheeler L, Mannino D. Relationship between asthma, overweight, and physical activity among U.S. high school students. J Commun Health. 2006;31(6):469-78.

47. Lochte L, Nielsen KG, Petersen PE, Platts-Mills TAE. Childhood asthma and physical activity: a systematic review with meta-analysis and Graphic appraisal tool for epidemiology assessment. BMC Pediatr. 2016;16(1):1-13.

48. Holstein B, Pedersen T, Bendtsen P, Madsen K, Meilstrup C, Nielsen L, et al. Perceived problems with computer gaming and internet use among adolescents: measurement tool for non-clinical survey studies. BMC Public Health. 2014;14(1):361.

\section{Ready to submit your research? Choose BMC and benefit from:}

- fast, convenient online submission

- thorough peer review by experienced researchers in your field

- rapid publication on acceptance

- support for research data, including large and complex data types

- gold Open Access which fosters wider collaboration and increased citations

- maximum visibility for your research: over $100 \mathrm{M}$ website views per year

At BMC, research is always in progress.

Learn more biomedcentral.com/submissions 